\title{
Cognitive computing for intelligent multimedia systems
}

C Springer Science+Business Media, LLC, part of Springer Nature 2020

Multimedia Tools and Applications gratefully acknowledges the editorial work of the scholars listed below on the special issue entitled "Cognitive Computing for Intelligent Multimedia Systems" (SI 1115 T).

Of 97 papers submitted to this issue, 42 were eventually accepted after a stringent peer review process.

\section{Corresponding Guest Editor}

\section{Yujie Li}

Fukuoka University, Japan

Email: yzyjli@gmail.com

\section{Guest Editors}

\section{Liao Wu}

Queensland University of Technology, Australia

Email: liao.wu@qut.edu.au

\section{Dong Wang}

Dalian University of Technology, China

Email: wdice@dlut.edu.cn

Publisher's note Springer Nature remains neutral with regard to jurisdictional claims in published maps and institutional affiliations. 